\title{
Financial Strain and Loneliness among Young Adults during the COVID-19 Pandemic: The Role of Psychosocial Resources
}

\author{
Tehila Refaeli * and Netta Achdut
}

check for updates

Citation: Refaeli, T.; Achdut, N. Financial Strain and Loneliness among Young Adults during the COVID-19 Pandemic: The Role of Psychosocial Resources. Sustainability 2021, 13, 6942. https://doi.org/ $10.3390 /$ su13126942

Academic Editor: Sajid Anwar

Received: 1 May 2021

Accepted: 18 June 2021

Published: 20 June 2021

Publisher's Note: MDPI stays neutral with regard to jurisdictional claims in published maps and institutional affiliations.

Copyright: (c) 2021 by the authors. Licensee MDPI, Basel, Switzerland. This article is an open access article distributed under the terms and conditions of the Creative Commons Attribution (CC BY) license (https:// creativecommons.org/licenses/by/ $4.0 /)$.
The Charlotte Jack Spitzer Department of Social Work, Ben-Gurion University of the Negev, Beer-Sheva 84105, Israel; nettaach@bgu.ac.il

* Correspondence: tehilare@bgu.ac.il; Tel.: +972-545885978
Abstract: The COVID-19 (2019 novel coronavirus) pandemic, which has been accompanied by an economic crisis and multiple restrictions on our lives, has sparked renewed interest in the topic of loneliness as well as its determinants. We examined (1) the association between financial strain, occurring upon the outbreak of the virus, and loneliness among Israeli young people (aged 20-35); (2) the associations between cognitive social capital, psychological resources, and loneliness; and (3) whether these social and psychological resources were moderators in the financial strain-loneliness link. A real-time survey based on snowball sampling was conducted during April $2020(\mathrm{~N}=426)$. Hierarchical linear models were employed to explore associations between financial strain, cognitive social capital, psychological resources, and loneliness. Financial strain emerging during the pandemic was associated with greater loneliness. Cognitive social capital and optimism decreased loneliness. Sense of mastery moderated the financial strain-loneliness link. Policymakers must develop and extend mental health initiatives aimed at alleviating the psychological consequences of the pandemic and must also combat financial strain via unemployment compensation and social assistance programs. In line with the United Nations sustainable development goals, these tasks should be viewed as an integral part of promoting public health.

Keywords: financial strain; perceived income adequacy; loneliness; coronavirus; optimism; mastery; cognitive social capital; young people

\section{Introduction}

The novel coronavirus outbreak is a crisis that began in the health domain but ledalmost simultaneously-to a crisis on the economic and social front. Following the declaration by the World Health Organization that COVID-19 (2019 novel coronavirus) met the criteria for a pandemic [1], many governments imposed restrictions of varying degrees of strictness that impacted people's day-to-day lives (see [2] for international comparison). The Israeli policy at the beginning of the crisis was dictated mainly by professionals at the Ministry of Health (public health experts and epidemiologists), who viewed the pandemic as a significant threat to public health in Israel and recommended far-reaching restrictions in all areas of life to prevent the virus from spreading. Israel, like many other Western democracies, has a national and comprehensive healthcare system that provides all Israeli citizens with equal and free access to health services. Under this system, special units within hospitals were built for COVID-19 patients, and other special facilities, such as "drive-in" centers for rapid virus tests, were placed throughout the country. The strict policy implemented by the Israeli government dictated not only the intensity of events in the labor market and the severity of the economic slump, but also immediately transformed many people's social lives. People were suddenly cut off from their workplaces, from routine activities, and from social interactions within informal and formal networks.

The Israeli policy included the shuttering of all educational institutions for children ages 0-18 (from mid-March until mid-May 2020) and comprehensive restrictions on the economic activity of many segments of the labor market (e.g., the closing of restaurants, 
entertainment venues, shops of all kinds, and hotels). Other restrictions were also imposed, such as staying at home except when absolutely necessary to go out, and a prohibition against congregating [3]. Furthermore, in April 2020, when this study was conducted, the Israeli government announced a lockdown and a 100-m limit on travel from home for nonessential activities. In this first phase of the pandemic, the Israeli public complied with the government's guidelines and behaved in accordance with "stay-at-home" orders. In a nationally representative survey conducted by the Israeli Central Bureau of Statistics (ICBS) [4] at the end of April 2020, when the data collection of the current study took place, around $90 \%$ of the population aged 21 and above reported that they were fully complying with the guidelines of the Ministry of Health. However, only about $38 \%$ of the population had great confidence in the government in dealing with the coronavirus crisis, and another 33\% reported that they trusted the government "to some extent." These rates further decreased during the second wave (July 2020) of the pandemic in Israel [5].

Since the beginning of the crisis, Israel has seen a sharp decline in its employment rate, a dramatic decline in household and business incomes, and an anomalous drop in gross domestic product (GDP) [6]. Unemployment rapidly went uphill from a low of 3.4\% in February to a peak of $26 \%$ by the end of April [7], and about one million employees $(942,000)$ were registered as new job seekers at employment service offices from mid-March to the end of April [8]. Additionally, due to the restrictions imposed on non-essential industries, many self-employed individuals were forced to close their businesses [6].

One of the groups particularly affected by the crisis, not only in Israel but in other OECD (The Organization for Economic Co-operation and Development) countries as well, is young people $[9,10]$. Out of one million new job seekers in Israel, almost half $(445,000)$, were between 18 and 35 years of age [8]. Young job seekers also have a lower chance of returning to their former workplaces, as many of them had been employed in the sectors most affected by the restrictions [9,11], such as restaurants, bars, event halls and other entertainment venues, sales, teaching, education, training provision, and non-professional occupations [12]. Indeed, in May 2020, and following a relaxation of many of the most severe restrictions, only about $18.5 \%$ of these young jobseekers returned to work [13]. At the time of this writing (February 2021), and following a second curfew imposed for six weeks starting in mid-September, unemployment remains extremely high, at around $18 \%$ [14], and many segments of the labor market have remained closed or were permitted to open only under strict instructions.

Young people being fired or furloughed are entitled to unemployment compensation. Some adjustments were made in the qualification period to give a greater number of new job seekers access to this program, and the duration of payment was expanded until June 2021. However, the replacement rate of unemployment benefit in Israel is relatively low, particularly for young adults [12]. Additionally, although a grant program to assist self-employed workers was introduced in the pandemic's initial phase, it was extremely limited. Consequently, poverty and financial strain have risen in Israel $[15,16]$, particularly among young people [16]. Similar trends, although to varying extents, have been observed in other OECD countries [11,17,18], among them the United States [19], Canada [20], and other European countries such as Greece and Poland [18]. A recent OECD survey [18] conducted among 25,000 respondents from 25 countries revealed that almost one-third of respondents reported financial difficulties since the start of the pandemic. Countries such as Mexico and Turkey showed the highest rate (around 65\%); Italy, Israel, and Spain scored in the middle with around 30\%; and countries such as Germany, Denmark, and the Netherlands scored at the bottom, with about $20 \%$ reporting financial difficulties in the wake of the pandemic. Furthermore, in all countries young people (18-29) were one of the groups most likely to report having run into financial difficulties since the start of the crisis [18]. Additionally, in a nationally representative survey conducted by the ICBS [4], $46 \%$ reported that their families' financial situation worsened following the crisis, half of the population feared that they would have difficulty in covering their monthly expenses, 
and $14 \%$ reported that they or one of their household members had reduced the amount of food or meals they ate during the past week.

The COVID-19 outbreak has affected not only the economic well-being of individuals and families but also greatly affected various aspects of their psychological well-being (e.g., $[17,21,22])$. A recent APA (American Psychological Association) poll indicated a sharp increase in the rate of people reporting anxiety in the United States during this global health crisis (62\%) compared to far lower levels in the previous three years (32-39\%) [23]. Although all age groups have been affected by the virus outbreak, a recent representative study of an adult population in the United States indicated that among young adults aged 18 to 29 years, symptoms of psychological distress were the highest compared to all other age groups [24]. In a national survey conducted among the Israeli population, $22 \%$ of those aged 21 and over reported that their mental state "worsened" or "greatly worsened" during the crisis. Further, feelings of stress and anxiety accompanied $34 \%$ of the population during this period, a feeling of depression accompanied $16 \%$ of the population, and a feeling of loneliness was reported by 24\% [4]. Moreover, in an Israeli COVID-19 study conducted among adults (aged 18 and above), Horesh et al. [25] found that age was negatively associated with anxiety, psychological distress, and financial worries. That is, younger responders were more prone to experiencing both adverse mental health and financial worries.

Although social distancing guidelines and restrictions are critical for curbing the spread of the virus, it is reasonable to suggest that they would lead to an increase in loneliness. Given that young adults are a high-risk group for loneliness, not only in ordinary times [26,27] but also during this pandemic [28], they are of particular concern.

The pandemic's ongoing effects in the economic and social arena, as well as the repeated and prolonged curfews imposed by governments in most Western countries, make the study of COVID-19-related loneliness and its determinants of great importance. Identifying those at higher risk for loneliness during this pandemic, as well as their potential resilience factors, is essential for designing and targeting effective measures to combat loneliness and its adverse consequences on individuals' life. Against this backdrop, the current study aimed to capture the role of financial strain, a major risk factor in the pandemic context, as well as cognitive social capital and psychological resources, as protective factors, in determining loneliness among Israeli young adults (20-35) during the initial phase of the pandemic in Israel. We then examined whether these psychosocial resources were moderators in the financial strain-loneliness link.

\subsection{Loneliness, Financial Strain, and Psychosocial Resources}

Loneliness stems from a lack of social interactions and relationships, or a gap between one's expectations of such relationships/interactions and one's reality [29]. Loneliness in recent years has been acknowledged as a public health problem, and the role played by socioeconomic inequality in loneliness has become more evident [30]. Associations have been found between loneliness and a number of factors: poorer physical and mental health, depression, depressive symptoms, suicidal ideation, and suicidal behavior [31-33]. Loneliness has also been found to be related to maladaptive behaviors such as drug use among adolescents and young adults [27]. Thus, an increase in loneliness, particularly among groups highly vulnerable to loneliness, such as young adults [26,27], is currently a major public health concern. Recent studies examining changes in loneliness among young adults during the COVID-19 pandemic have yielded mixed findings. Whereas Luchetti et al. [34] found no evidence for a rise in loneliness, Lee et al. [35] did find such a rise. Further, loneliness in the wake of the pandemic was found to be related to psychological distress among the general population in Israel (aged 18 and above) [25] and to depression among young adults [35], with younger age groups being one of the groups at highest risk for experiencing loneliness [36].

Financial strain, particularly when long-lasting, is known to have severe consequences for the physical and mental well-being of individuals and families [20,37], including the 
subjective feeling of loneliness [38-40]. Although we could not find studies examining the financial strain-loneliness association in the wake of the current crisis, recent COVID19 studies have demonstrated the negative effect of financial strain on mental health outcomes [22], including psychological distress [21,24], depressive symptoms and the exacerbation of symptoms over time [41], and the risk of suicide attempts [42].

Various psychosocial resources are protective against loneliness. A central one is social capital, a multidimensional concept that can be divided into structural and cognitive components. Whereas structural social capital refers to the extent and intensity of social connections, the cognitive part refers mainly to the subjective perception of support and trust $[43,44]$. In other words, "these two components can be respectively characterized as what people 'do' and what people 'feel' in terms of social relations" ([44], p. 106). In light of the restrictions on social gatherings and social activity (social capital's structural component), and the April 2020 lockdown in Israel, the cognitive component seemed more appropriate than the structural component in terms of measuring social capital and the effect of this construct on loneliness during the pandemic. The protective role of different constructs of cognitive social capital, such as perceived support, social trust, and satisfaction with different types of social relationships against loneliness, is well documented (C.Y.S. [45-48]).

Several psychological resources might also be important for alleviating loneliness, among them optimism and sense of mastery. Optimism is defined as a personality construct characterized by a general tendency to expect positive outcomes, or the belief that "good as opposed to bad things will, in general, occur in one's life" ([48], p. 26). One key implication of this personality characteristic is that, at times of stress, optimists tend to cope better. When there is a limited ability to cope in a "problem-focused" way, as was the case at the beginning of the pandemic, optimists are likely to employ cognitive coping strategies that are more adaptive, such as positively reinterpreting the situation [49]. Although empirical evidence is quite limited, a few studies have demonstrated the protective role of optimism against loneliness in different age groups [50,51].

Sense of mastery refers to the perceived control that individuals have over their future and to their perceived ability to influence important aspects of their lives and cope with life stressors $[52,53]$. There is an association between mastery and cognitive coping strategies that may lead to a change in one's perceptions of stressful life events and are particularly critical at a time of macro crisis, such as the COVID-19 pandemic and the financial distress that has arisen as a result. A recent review of the literature indicated that a greater sense of mastery decreases feelings of loneliness across ages [54]. Several mechanisms might explain this finding, among them the active coping strategies that people with high levels of mastery deploy to change the unpleasant situation in which they find themselves [54]. However, the ability to make changes can be quite limited in a time of global crisis, such as the current pandemic, and might affect the expected contribution of mastery to loneliness.

Some previous evidence supports the possibility that the psychosocial resources examined in this study are moderators in the financial strain-loneliness association. For example, different aspects of social support and social capital were found to moderate the association between low income and financial distress on the one hand, and loneliness on the other, in routine times [55-57]. Other studies have suggested that different psychological resources are moderators in the economic distress-mental distress link, among them optimism [58] and mastery $[59,60]$. However, to the best of our knowledge, no study has considered the kinds of diverse psychosocial resources suggested here as possible moderators in the financial distress-loneliness association, particularly among young adults, let alone in the context of the current pandemic.

\subsection{Theoretical Framework}

The stress process model refers to the effects of stress on mental health in general and suggests that stressors such as poverty and financial strain are stressful life conditions that can impair an individual's psychological well-being [61,62]. According to Pearlin's 
model [61], suffering from financial strain, particularly over long periods of time, increases the probability of experiencing stress-inducing factors such as lack of resources, limited opportunities, and low self-regard, and limits access to privileges and security. That is, significant stressors rarely occur in a vacuum, and one stressor is very likely to trigger others. For example, financial strain can lead to secondary stressors related to family conflict and withdrawal from social interactions and activities: stressors which in and of themselves have long-lasting effects on mental health even after the original stressor no longer exists [63]. In the context of the current pandemic, financial strain might, for instance, lead to dropout from higher education and thus affect the entire life course of young people and their prospects in the labor market. Accordingly, in this study, we assumed that although the stress associated with the pandemic, along with the ongoing restrictions on people's social lives, increased feelings of loneliness among many, it had a greater detrimental effect on people who experienced additional stressors in the wake of the crisis, such as financial strain. The stress process model also highlights the fact that various psychological resources (e.g., coping strategy, sense of mastery) and social resources (social support) can moderate the stress-distress association [60,61]. These moderators are viewed as factors that intervene in and buffer the negative effect of stress on distress, but not as factors that prevent the stressor from occurring in the first place. On the basis of the ideas of Pearlin [61] and of Pearlin and Lieberman [62], in this study, we considered financial strain in the wake of the pandemic as the stress factor, and loneliness served as the psychological distress outcome. In addition, following the stress process moderation model [60,61], we examined the role of cognitive social capital as well as psychological resources as factors that might moderate the financial strain-loneliness link.

\subsection{The Current Study}

Since the outbreak of the pandemic, widening social and economic gaps worldwide have raised major concerns regarding growing health disparities, not only among less privileged vs. more privileged socioeconomic groups, but also among those groups most affected by either the economic crisis (young adults, for example) or the health crisis (the elderly). Against this background, we examined the role of COVID-19-related financial strain in determining loneliness among young adults. This study is one of only a very few studies exploring loneliness among young adults in the wake of the pandemic and employed a comprehensive model examining the association between various risk and protective factors particularly relevant to the current crisis, as well as loneliness.

On the basis of the stress-distress model [61,62], we hypothesized that: (1) financial strain in the wake of the pandemic would be associated with increased loneliness, (2) greater psychosocial resources would be associated with decreased loneliness, (3) the effect of financial strain on loneliness would be lessened by greater social capital and psychological resources.

\section{Methods}

\subsection{Sample}

The only inclusion criterion in this study was being an Israeli young man or woman between the ages of 20 and 35, and the exclusion criterion was currently being in mandatory military service. The study's sample comprised 426 young people between the ages of 20 and $35(\mathrm{M}=26.89, \mathrm{SD}=4.0)$. This final number was arrived at after we excluded $6.2 \%$ $(n=28)$ of the 454 participants who completed the questionnaire as they were performing their compulsory military service. The reason for excluding this group was that they receive all their material needs, including a monthly allowance, from the Israel Defense Forces (IDF), a situation that did not change following the pandemic. Thus, young people who were fulfilling their mandatory service during COVID-19 were not assumed to experience pandemic-related financial strain. The vast majority of participants $(95.1 \%)$ were Israeliborn, and almost all (95.0\%) were Jewish. A minority (5\%) were immigrants, and most of them were from the Former Soviet Union. In terms of other demographics, about one-fifth 
(22.1\%) were married, $59.3 \%$ had a post-secondary education, and $54.1 \%$ were students. In terms of COVID-19, no participant had contracted it prior to the study or at the time of the survey.

\subsection{Process}

Data were collected during a time of severe COVID-19 restrictions in Israel: April and the first week of May 2020. An online snowball sampling method was used to draw the sample. Using WhatsApp and Facebook, the researchers shared a link to the questionnaire, and on a weekly basis posted this link on relevant Facebook groups (i.e., those of young adults). Participants were asked to share the link with friends and family in whatever way they wished. Given the frequent use of social media by young people, the researchers' use of the snowball sampling method was more direct and purposeful than if any other type of non-probability sampling method had been used. It should be noted that online snowball sampling does not allow one to assess the response rate because there is no way to determine exactly how many people are not responding to the link that they have presumably received.

\subsection{Measurement}

\subsubsection{Dependent Variable}

Loneliness was measured in two ways. First of all, it was measured by the following standard single item: "How often have you felt lonely in the last two weeks?" Singleitem measurements have been widely used (e.g., [29,64]); they have also been used as dependent variables [65,66]. Additionally, Nicolaisen and Thorsen [65] provided a validity test for measuring loneliness with a single ordinal item. Answers were provided on a four-point Likert scale ( 1 = often; 2 = sometimes; $3=$ seldom; $4=$ never). For the purpose of bivariate analysis, we merged the categories of feeling lonely never and infrequently into one category that we designated "infrequently-never" (preliminary analysis showed small or no differences between these categories across all study variables), thereby yielding three categories of loneliness: infrequently or never felt lonely $(=0)$, sometimes felt lonely $(=1)$, and felt lonely often (=2). Second of all, a change in the subjective feeling of loneliness was measured by: "Since the outbreak of the coronavirus crisis, have you felt lonelier than before (during routine times)?" Answers were provided on a four-point Likert scale (no, my feeling of loneliness before the crisis and today is similar $=1$; yes, slightly lonelier than before $=2$; yes, lonelier than before $=3$; yes, much lonelier than before $=4$ ). On the basis of this item, we created a dummy variable where participants who reported that they were lonelier, to any extent, than before, received the value 1 . Spearman's correlation between the two measures of loneliness was 0.54 .

\subsubsection{Independent Variables}

Financial strain was assessed via two questions referring to perceived income adequacy (PIA): (1) PIA during routine times was assessed by the question: "Do you usually, in routine times, manage to cover all your monthly expenses for food, electricity, telephone, etc.?" Answers were provided on a four-point Likert scale (yes, without any difficulty $=1$; yes, but with some difficulty = 2; no, not so well = 3; no, not at all =4). On the basis of this item, we created a dummy variable where participants who reported that they were unable to meet their expenses-"no, not so well" and "no, not at all"-received the value (1). Similar items have been used in previous studies to evaluate one's subjective social position (e.g., [56,67]) and to assess financial strain in the wake of the pandemic [17]; (2) PIA during the COVID-19 pandemic was assessed by the question: "Has there been an adverse change in your ability to cover your household monthly expenses since the COVID-19 outbreak?" (1 = yes). Spearman's correlation between the financial strain measures was 0.33 .

Cognitive social capital was measured via five items, the first three of which were: (1) satisfaction from relationships with family members; (2) satisfaction from relationships with friends; (3) satisfaction from relationships with neighbors. Each of these items was 
measured on a four-point Likert scale $(0=$ not satisfied at all; $1=$ not so satisfied; 2 = satisfied; 3 = very satisfied). For the purpose of the bivariate analysis and due to small cell constraints, we merged, for each of the above measures, the first two categories $(0=$ not satisfied at all/ not so satisfied) and the last two categories ( 1 = satisfied/ very satisfied). The last two items of this measure were: (4) "If you were in trouble, are there people whose help you could count on?" (1 = yes), a parameter defined as perceived support, and (5) "In general, can you trust most people or do you have to be wary of them?" $(0=$ you have to be wary of people; 1 = most people can be trusted), a parameter defined as perceived trust. These items were taken from the Israeli Social Survey that was designed and conducted by the ICBS [68] and are widely used to measure the cognitive construct of social capital [69-71].

Sense of mastery was derived from the scale developed by Pearlin and Schooler [72], which comprises seven statements regarding participants' feeling of being able to control things in their lives, for example, "I have little control over the things that happen to me" and "What happens to me in the future mostly depends on me." Participants were asked to indicate, on a scale ranging from 1 (strongly agree) to 5 (strongly disagree), the extent to which each statement described them. The index is calculated as the sum of the items. This scale was translated into Hebrew and validated by Hobfoll and Walfish [53]. Cronbach's alpha was 0.88 for the original questionnaire [53], and it was 0.78 in the present study.

Optimism was measured by The Life Orientation Test (LOT-R) [73]. This scale includes 10 items with four filler items. Respondents were asked to indicate their level of agreement with each item, such as "In uncertain times, I usually expect the best" and "If something can go wrong for me, it will," on a scale of 1 (strongly agree) to 4 (strongly disagree). The scale was translated into Hebrew and validated by Zeidner and Ben Zur [74]. Cronbach's alpha was 0.63 for the original questionnaire [74], and it was 0.83 in the present study.

Control variables (demographics) included age, gender, marital status, parenthood status, education, parental education (as an indication of family background and resources), currently studying (yes/no), employment status (employed/not employed), and physical health problem (suffering/not suffering from a health problem or a limitation that lasted at least six months).

\subsection{Data Analysis}

In the first step of the analysis, we conducted two categorical principal component analyses (CATPCA): (1) A CATPCA with promax rotation-an oblique rotation option that assumes that the items tested are highly correlated [75]—-was used to explore whether the two items of loneliness (reports on subjective feelings of loneliness in the last two weeks; increase in feelings of loneliness since the coronavirus outbreak) could be treated as a single construct. For further explanation of CAPCA, see Refaeli and Achdut [56].

CATPCA for the loneliness items yielded a one-factor solution that contained the two items that loaded significantly: (1) subjective feeling of loneliness (loading $=0.90$ ) and (2) exacerbation of the feeling of loneliness during the coronavirus outbreak (loading $=0.76$ ) with an eigenvalue of 1.43 . The cumulative explained variance by this factor stood at 71.7\%. Following Kapucu et al. [76], we applied Bartlett's test of sphericity and KMO to the original data (see also example in [77]). Sampling adequacy was supported by KMO and Bartlett's test at 0.51 , with a statistically significant test of sphericity $(p<0.001)$. Finally, we calculated factor scores for each individual respondent using the least squares regression, which has the highest validity of the factor scoring techniques [78]. A higher score for this factor indicates a greater subjective feeling of loneliness and an exacerbation of this feeling during the pandemic.

(2) A categorical principal component analysis (CATPCA) with varimax rotation was used to explore the underlying constructs of cognitive social capital (satisfaction with family, friend, and neighbor relationships; perceived support; perceived trust).

Categorical principal component analysis (CATPCA) for the cognitive social capital items yielded a one-factor solution that contained four items that loaded significantly: 
(1) satisfaction with family relationships (loading $=0.57)$, (2) satisfaction with friend relationships (loading $=0.72$ ), (3) satisfaction with neighbor relationships (loading $=0.67$ ), and $(4)$ perceived support (loading $=0.67$ ), with an eigenvalue of 1.75 . The cumulative explained variance by this factor stood at $43.8 \%$. Sampling adequacy was supported by $\mathrm{KMO}$ and Bartlett's test, at 0.72 , with a statistically significant test of sphericity $(p<0.001)$. Here, also, on the basis of the transformed variables, we calculated factor scores for each individual respondent using the least squares regression [78]. The higher the score for this factor, the greater the social capital. Perceived trust was not highly correlated with the other components, and therefore we treated it as a distinct variable.

In the second step, we provided descriptive statistics of the study variables in the overall sample and by financial strain emerging in the wake of the COVID-19 outbreak. $t$-tests were computed in order to assess differences in financial strain by continuous independent variables and chi squared for differences by categorical variables.

In the third step, we employed a bivariate analysis to assess the associations between the dependent variable - the loneliness factor solution score, hereafter loneliness-and financial strain, social capital (social capital factor score, perceived trust), and psychological resources (sense of mastery, optimism). $t$-tests were computed in order to assess differences in loneliness by dichotomous independent variables, and Pearson's correlation was employed for continuous independent variables.

In the fourth step, a four-step hierarchical linear regression model estimated loneliness. In the first model, we included sociodemographic characteristics, physical health status, employment status, and financial strain in routine times. To study the distinct contribution made by financial strain in the wake of the coronavirus outbreak to loneliness, in the second model, we added financial strain during the crisis. In the third model, we added the social capital factor score, perceived trust, and the psychological resources of optimism and sense of mastery. Finally, to examine whether the magnitude of the effect of financial strain varied among participants with different levels of psychosocial resources, we added to the regression model two-way interaction terms between financial strain and each resource (social capital factor, trust, optimism, sense of mastery) (Model 4). Due to multicollinearity between these interaction terms and small cell constraints, we could not include all the interaction terms in a single model. Thus, we estimated our model with one interaction term at a time. Data were analyzed using IBM SPSS ver. 26 Statistics for windows.

\subsection{Ethical Considerations}

The study adhered to the authors' university's ethical guidelines and received approval from the Ethics Committee of the Department of Social Work at Ben-Gurion University of the Negev (Approval number: \#50520). Participants gave their informed consent, electronically, and were assured of confidentiality. The questionnaire did not include any details that would enable participants' identification.

\section{Results}

Table 1 summarizes the descriptive statistics of the study variables in the overall sample and by financial strain. More than one-third (37.6\%) of the study participants reported emerging financial strain in the wake of the pandemic (i.e., emerging hardship in covering household expenses following the COVID-19 outbreak). We found statistically significant differences by financial strain in several measures: young people, both of whose parents had a college/university education (a solid indication of family resources), were less likely to report emerging financial strain in the wake of the pandemic. As expected, employed participants were less likely to report financial strain, and participants who in routine times already had difficulty covering their monthly expenses were more likely to further suffer from financial strain in the wake of the pandemic. Satisfaction with family relations, perceived support, and perceived trust were more prevalent among those who managed to cover their household expenses during the pandemic than those who reported financial strain. With respect to the psychological resources of optimism and mastery, both 
were lower among young adults who reported financial strain. Finally, financially strained participants were far more likely to report often feeling lonely compared to participants with no financial difficulties (31.3\% and $16.6 \%$, respectively), and they were also much more likely to report an increase in their feelings of loneliness in the wake of the pandemic (62.5\% and $41.5 \%$, respectively).

Table 1. Descriptive statistics of the study variables by financial strain during the pandemic, $N=426$.

\begin{tabular}{|c|c|c|c|c|}
\hline & \multicolumn{4}{|c|}{ Financial Strain during the Pandemic } \\
\hline & Overall & No $(N=265)$ & Yes $(N=161)$ & $t /$ Chi-Square \\
\hline & $100 \%$ & $62.2 \%$ & $37.6 \%$ & \\
\hline & \%/Mean (SD) & $\% /$ Mean (SD) & $\% /$ Mean (SD) & \\
\hline Age & $26.89(4.0)$ & $27.07(4.08)$ & $26.56(3.73)$ & $t=1.31$ \\
\hline Gender & & & & $\chi^{2}=0.59$ \\
\hline Male & 20.7 & 21.9 & 18.8 & \\
\hline Female & 79.3 & 78.1 & 81.3 & \\
\hline Marital status & & & & $\chi^{2}=1.68$ \\
\hline Married & 22.1 & 24.2 & 18.8 & \\
\hline Other & 77.9 & 75.8 & 81.3 & \\
\hline Have kids & & & & $x^{2}=3.05$ \\
\hline Yes & 18.8 & 21.1 & 13.7 & \\
\hline No & 81.2 & 78.9 & 86.3 & \\
\hline Education & & & & $\chi^{2}=0.70$ \\
\hline Secondary education & 40.7 & 42.3 & 38.1 & \\
\hline Post-secondary education & 59.3 & 57.7 & 61.9 & \\
\hline Parents' education & & & & $\chi^{2}=7.81^{* *}$ \\
\hline Both college/university & 44.9 & 50.2 & 36.3 & \\
\hline Other & 55.1 & 49.8 & 63.7 & \\
\hline Currently studying & & & & $\chi^{2}=0.08$ \\
\hline Yes & 54.1 & 53.8 & 45.0 & \\
\hline No & 45.9 & 46.4 & 55.0 & \\
\hline Employment status & & & & $\chi^{2}=11.83^{* *}$ \\
\hline Employed & 55.1 & 61.5 & 44.4 & \\
\hline Not employed & 44.9 & 38.5 & 55.6 & \\
\hline Physical health problem & & & & $\chi^{2}=1.08$ \\
\hline Yes & 16.9 & 15.5 & 19.4 & \\
\hline No & 83.1 & 84.5 & 80.6 & \\
\hline Financial strain in routine times & & & & $x^{2}=46.01^{* *}$ \\
\hline Difficulties in covering monthly expenses & 13.2 & 4.5 & 27.5 & \\
\hline No difficulties in covering monthly expenses & 86.8 & 95.5 & 72.5 & \\
\hline Family relations & & & & $x^{2}=3.95^{*}$ \\
\hline Not satisfied at all or not so satisfied & 12.3 & 9.8 & 16.4 & \\
\hline Satisfied or very satisfied & 87.7 & 90.2 & 83.6 & \\
\hline Friend relations & & & & $\chi^{2}=0.79$ \\
\hline Not satisfied at all or not so satisfied & 9.7 & 8.7 & 11.3 & \\
\hline Satisfied or very satisfied & 90.3 & 91.3 & 88.7 & \\
\hline
\end{tabular}


Table 1. Cont.

\begin{tabular}{|c|c|c|c|c|}
\hline & \multicolumn{4}{|c|}{ Financial Strain during the Pandemic } \\
\hline & Overall & No $(N=265)$ & Yes $(N=161)$ & t/Chi-Square \\
\hline & $100 \%$ & $62.2 \%$ & $37.6 \%$ & \\
\hline & $\% /$ Mean (SD) & \%/Mean (SD) & $\% /$ Mean (SD) & \\
\hline Neighbor relations & & & & $x^{2}=0.06$ \\
\hline Not satisfied at all or not so satisfied & 32.1 & 32.2 & 31.8 & \\
\hline Satisfied or very satisfied & 67.9 & 67.8 & 68.2 & \\
\hline Perceived support & & & & $\chi^{2}=19.45^{* *}$ \\
\hline Yes & 89.6 & 94.7 & 81.3 & \\
\hline No & 10.4 & 5.3 & 18.8 & \\
\hline Cognitive social capital factor & $-0.01(1.00)$ & $0.09(0.88)$ & $-0.15(1.14)$ & $t=0.69^{* *}$ \\
\hline Perceived trust & & & & $\chi^{2}=7.97 * *$ \\
\hline Yes & 62.4 & 67.5 & 46.2 & \\
\hline No & 37.6 & 32.5 & 53.8 & \\
\hline Optimism (6-30) & $20.76(4.49)$ & $\begin{array}{l}20.97 \\
(4.56)\end{array}$ & $\begin{array}{l}19.95 \\
(4.48)\end{array}$ & $t=2.24 *$ \\
\hline Mastery (7-35) & $25.92(4.63)$ & $\begin{array}{l}26.41 \\
(4.85)\end{array}$ & $\begin{array}{l}24.78 \\
(4.42)\end{array}$ & $t=3.44^{* *}$ \\
\hline Loneliness & & & & $x^{2}=14.82^{* *}$ \\
\hline Infrequently/never & 39.5 & 44.9 & 30.6 & \\
\hline Sometimes & 38.4 & 38.5 & 38.1 & \\
\hline Often & 22.1 & 16.6 & 31.3 & \\
\hline $\begin{array}{l}\text { Feeling more loneliness during the } \\
\text { pandemic }\end{array}$ & & & & $\chi^{2}=17.58^{* *}$ \\
\hline Yes & 49.4 & 41.5 & 62.5 & \\
\hline No & 50.6 & 58.5 & 37.5 & \\
\hline
\end{tabular}

Note. ${ }^{*} p<0.05 ;{ }^{* *} p<0.01$.

Table 2 presents the mean value (SD) of loneliness by financial strain, social capital constructs, social capital factor score, optimism, and sense of mastery. Loneliness was related to almost all indices considered, with the exceptions of neighbor relations and perceived trust. Participants who experienced a change in their ability to cover their household expenses in the wake of the crisis reported greater loneliness than did those who did not experience such distress. Loneliness was also higher for participants with lower satisfaction from family and friend relationships, as well as those with no perceived support. Pearson's correlation between loneliness and the social capital factor indicated a negative association. Optimism and sense of mastery were also negatively correlated with loneliness.

Table 3 shows the four-step hierarchical linear regression analysis. The dependent variable in all models was loneliness. Coefficients (standard errors in parentheses) and standard coefficients of the independent variables are presented. According to the first model, men, married participants, and those employed had lower feelings of loneliness. Having a health problem was positively correlated with loneliness. Participants' sociodemographic characteristics accounted for $4.8 \%$ of the explained variance in subjective loneliness (Model 1). The second model indicated that financial strain in the wake of the crisis was positively correlated with loneliness. This step, including financial strain only, made a distinct contribution of $4.5 \%$ to the total explained variance (Model 2). The third model indicated that social capital and optimism were negatively associated with loneliness. That is, having greater social capital and optimism was associated with decreased loneliness. These resources made a substantial and distinct contribution to the total explained vari- 
ance $(9.1 \%$ ) (Model 3). To the final model, we added, in turn, a two-way interaction term between financial strain in the wake of the crisis and each psychosocial resources measure (cognitive social capital, trust, optimism, and sense of mastery). We found that although sense of mastery appeared insignificant in explaining loneliness in the main effect model, it moderated the negative effect of emerging financial strain in the wake of the pandemic on loneliness. Participants who reported that they were financially distressed were less likely to feel lonely if they possessed a greater sense of mastery compared to those with a lower sense of mastery. This finding suggests that the effect of financial strain on loneliness was less pronounced among those with a greater sense of mastery (Model 4). We found no further evidence of moderation - the effect of financial strain on loneliness appeared to be uniform across participants, regardless of their different levels of social resources and optimism (not shown). Estimations derived from the models, including non-significant interaction effects, are available upon request.

Table 2. Loneliness by financial strain, social capital, and psychological resources variables $(\mathrm{N}=426)$.

\begin{tabular}{|c|c|c|}
\hline & Loneliness (SD) & $t$-Test/Pearson's Correlation \\
\hline Financial strain during the pandemic & & $t=-5.16^{* *}$ \\
\hline Emerging difficulties in covering monthly expenses & $0.31(0.96)$ & \\
\hline No difficulties in covering monthly expenses & $-0.19(0.97)$ & \\
\hline Family relations & & $t=4.14^{* *}$ \\
\hline Not satisfied at all or not so satisfied & $0.52(0.79)$ & \\
\hline Satisfied or very satisfied & $-0.08(1.00)$ & \\
\hline Friend relations & & $t=2.05^{*}$ \\
\hline Not satisfied at all or not so satisfied & $0.29(0.92)$ & \\
\hline Satisfied or very satisfied & $-0.04(1.00)$ & \\
\hline Neighbor relations & & $t=1.49$ \\
\hline Not satisfied at all or not so satisfied & $0.09(0.97)$ & \\
\hline Satisfied or very satisfied & $-0.06(1.00)$ & \\
\hline Perceived support & & $t=2.53 *$ \\
\hline No & $0.35(0.94)$ & \\
\hline Yes & $-0.04(0.99)$ & \\
\hline Cognitive social capital factor & & $r=-0.26^{* *}$ \\
\hline Perceived trust & & $t=0.77$ \\
\hline No & $0.04(1.00)$ & \\
\hline Yes & $-0.03(0.99)$ & \\
\hline Optimism (6-30) & & $\mathrm{r}=-0.30^{* *}$ \\
\hline Mastery (7-35) & & $\mathrm{r}=-0.26^{* *}$ \\
\hline
\end{tabular}

Note. ${ }^{*} p<0.05 ; * * 0.01$.

The coefficient of financial strain remained significant across the four models estimated. That is, all else being equal, financial strain positively associated with loneliness. In the final model, financial strain also had the larger standardized coefficient, compared to all of the other explanatory variables, and thus had the strongest effect on loneliness. The entire set of independent variables accounted for $18.8 \%$ of the variance in loneliness, $F(15,418)=7.26$, $p<0.001$. 
Table 3. Hierarchical multiple regression analysis for predicting loneliness (OLS).

\begin{tabular}{|c|c|c|c|c|c|c|c|c|}
\hline & \multicolumn{2}{|c|}{ Model 1} & \multicolumn{2}{|c|}{ Model 2} & \multicolumn{2}{|c|}{ Model 3} & \multicolumn{2}{|c|}{ Model 4} \\
\hline & B (SE) & B & B (SE) & $\beta$ & B (SE) & $\beta$ & B (SE) & $\beta$ \\
\hline Age & $0.007(0.01)$ & 0.029 & $0.007(0.01)$ & 0.016 & $0.007(0.01)$ & 0.027 & $0.008(0.01)$ & 0.033 \\
\hline Gender $($ male $=1)$ & $\begin{array}{c}-0.233 * \\
(0.12)\end{array}$ & -0.094 & $\begin{array}{l}-0.213 \\
(0.11)\end{array}$ & 0.117 & $\begin{array}{l}-0.238^{* *} \\
(0.11)\end{array}$ & -0.096 & $\begin{array}{l}-0.240 * \\
(0.11)\end{array}$ & -0.097 \\
\hline $\begin{array}{l}\text { Marital status } \\
(\text { married }=1)\end{array}$ & $\begin{array}{c}-0.443^{* *} \\
(.13)\end{array}$ & -0.184 & $\begin{array}{l}-0.418^{* *} \\
(0.13)\end{array}$ & 0.136 & $\begin{array}{c}-0.254^{*} \\
(0.13)\end{array}$ & -0.105 & $\begin{array}{c}-0.255^{*} \\
(0.13)\end{array}$ & -0.106 \\
\hline $\begin{array}{c}\text { Education } \\
(\text { post-secondary }=1)\end{array}$ & $0.041(0.14)$ & 0.020 & $0.014(0.11)$ & 0.111 & $0.031(0.10)$ & 0.015 & $0.028(0.10)$ & 0.014 \\
\hline $\begin{array}{c}\text { Parents' education } \\
\text { (both } \\
\text { college/ university = 1) }\end{array}$ & $\begin{array}{l}-0.017 \\
(0.09)\end{array}$ & -0.008 & $0.022(0.09)$ & 0.096 & $0.057(0.09)$ & 0.029 & $0.073(0.09)$ & 0.037 \\
\hline $\begin{array}{l}\text { Currently studying } \\
(\text { yes }=1)\end{array}$ & $0.037(0.10)$ & 0.018 & $0.053(0.10)$ & 0.100 & $0.069(0.09)$ & 0.034 & $0.085(0.09)$ & 0.043 \\
\hline $\begin{array}{l}\text { Financial strain in } \\
\text { routine times } \\
\text { (difficulties in } \\
\text { covering monthly } \\
\text { expenses }=1 \text { ) }\end{array}$ & $0.037(0.14)$ & 0.013 & $\begin{array}{c}-0.163 \\
(0.15)\end{array}$ & 0.150 & $\begin{array}{c}-0.372 * \\
(0.15)\end{array}$ & -0.127 & $\begin{array}{c}-0.399 * * \\
(0.15)\end{array}$ & -0.136 \\
\hline Employed (= 1) & $\begin{array}{l}-0.261 * * \\
(0.10)\end{array}$ & -0.130 & $\begin{array}{c}-0.194^{* *} \\
(0.09)\end{array}$ & 0.098 & $\begin{array}{c}-0.172 \\
(0.09)\end{array}$ & -0.086 & $\begin{array}{l}-0.170 \\
(0.09)\end{array}$ & -0.085 \\
\hline $\begin{array}{l}\text { Physical health } \\
\text { problem }(\text { yes = 1) }\end{array}$ & $\begin{array}{l}0.242 * \\
(0.13)\end{array}$ & 0.091 & $0.228(0.12)$ & 0.126 & $0.102(0.12)$ & 0.038 & $0.118(0.12)$ & 0.044 \\
\hline $\begin{array}{l}\text { Financial strain } \\
\text { during pandemic } \\
\text { (difficulties in } \\
\text { covering monthly } \\
\text { expenses }=1 \text { ) }\end{array}$ & & & $\begin{array}{c}0.474^{* *} \\
(0.10)\end{array}$ & 0.104 & $\begin{array}{l}0.454^{* *} \\
(0.10)\end{array}$ & 0.220 & $\begin{array}{l}1.466^{* *} \\
(0.53)\end{array}$ & 0.711 \\
\hline $\begin{array}{l}\text { Cognitive social } \\
\text { capital factor }\end{array}$ & & & & & $\begin{array}{l}-0.154^{* *} \\
(0.05)\end{array}$ & -0.154 & $\begin{array}{c}-0.153^{* *} \\
(0.54)\end{array}$ & -0.153 \\
\hline Perceived trust & & & & & $0.160(0.09)$ & 0.078 & $0.163(0.09)$ & 0.079 \\
\hline Mastery (7-35) & & & & & $\begin{array}{c}-0.021 \\
(0.01)\end{array}$ & -0.101 & $\begin{array}{c}-0.008 \\
(0.01)\end{array}$ & -0.039 \\
\hline Optimism (6-30) & & & & & $\begin{array}{c}-0.038^{* *} \\
(0.01)\end{array}$ & -0.174 & $\begin{array}{l}-0.038^{* *} \\
(0.01)\end{array}$ & -0.175 \\
\hline $\begin{array}{c}\text { Financial strain } \\
\text { during pandemic * } \\
\text { Mastery }\end{array}$ & & & & & & & $\begin{array}{l}-0.040 * \\
(0.02)\end{array}$ & -0.488 \\
\hline Constant & $0.011(0.41)$ & & $\begin{array}{c}-0.191 \\
(0.40)\end{array}$ & & $1.030(0.49)$ & & $0.631(0.53)$ & \\
\hline $\mathbf{R}^{2}$ & 0.048 & & 0.093 & & 0.178 & & 0.188 & \\
\hline$R^{2}$ Change & & & $0.045^{* *}$ & & $0.091 * *$ & & $0.01 *$ & \\
\hline
\end{tabular}

\section{Discussion}

The COVID-19 pandemic has affected people's well-being through diverse paths. Two major paths are rooted in the deep and continuous financial crisis and the ongoing restrictions on people's social lives. Although the pandemic poses a low threat to the physical health of young people, it affects their lives in many other ways, exposing them to multiple social and economic stressors. The social and work lives of young people have been extremely damaged in the wake of the COVID-19 outbreak. Many of them live alone 
and have not been able to visit their family members, including their parents, or meet their friends. Entertainment venues, such as clubs, bars, and movie theaters, closed down. Post-secondary education institutes were also closed, then transitioned to online learning, and extremely high rates of young people in these age groups lost their jobs $[9,10]$. In sum, the cessation of all leisure and social activities has put young people at high risk for loneliness and its adverse consequences.

Against this backdrop, in the current study we explored whether the financial strain that emerged at the beginning of the pandemic was associated with greater loneliness among young adults in Israel. We further explored the association between various psychosocial resources and loneliness, and whether these resources were moderators in the financial strain-loneliness association. Given the far-reaching implications of loneliness for the health and mental health of individuals [31-33], including its effect on substance abuse in the wake of the pandemic $[79,80]$, and the clear evidence of the centrality of loneliness in mental health disparities during the pandemic [81,82], exploring the factors that pose risks as well as those that might protect people from loneliness in the context of the pandemic is essential.

In line with recent COVID-19 studies suggesting the high vulnerability of young adults to loneliness $[28,36,83]$, half of the participants in this study reported that they felt lonelier now than they did before the novel coronavirus outbreak. This finding can be attributed to the likelihood that those who had had more intense activity and interactions within their social networks prior to the pandemic (i.e., young adults, in accordance with this life phase) experienced greater disruptions in their social life and subsequently experienced a greater increase in loneliness. Similarly, Lee et al. [35] suggested that the social restrictions that followed the pandemic's outbreak led to high rates of loneliness particularly among those with previously stronger social networks.

In line with our hypothesis, we found that the financial strain that emerged in the wake of the pandemic was associated with increased loneliness. Young people who had difficulties covering their monthly expenses during this period were more prone to experiencing loneliness, even after adjusting for financial strain in routine times. This finding aligns with the stress process model, suggesting that economic distress is associated with adverse mental health outcomes [62,63]. This association might be the result of some of the effects of financial strain, including an increase in the sense of insecurity and hopelessness about the future [62,84], both of which may be related to higher loneliness. Similarly, Dawel et al. [85] found that the financial distress resulting from the pandemic was strongly associated with worse mental health. Young people who have experienced financial strain during this crisis period have also been exposed to secondary stressors such as strains on family, marital, and other intimate relationships, and on their ability to start or continue their higher education. These secondary stressors can have longlasting effects on mental health, even after the original stressor (i.e., the financial strain) no longer exists [63]. Furthermore, "stress proliferation" [63] - that is, the notion that early stressful circumstances affect the life courses of young people and cause additional stressful circumstances later-may also come into play. Stress proliferation poses barriers to status attainment and steers people towards lower occupational and economic statuses, setting in motion a chain of adverse events which can affect people's mental health. Accordingly, we can assume that the COVID-19 crisis and its associated consequences will have longlasting effects on young people's mental well-being many years after the pandemic itself is eradicated. Further, given the prolonged nature of the current pandemic and the ongoing economic crisis, which has been accompanied by high unemployment in most Western countries, economic disparities are expected to grow over time [86], even long after the pandemic has passed [87]. This expected trajectory will further deepen and expand mental health disparities, making socioeconomic inequality in health a matter of urgent priority.

With respect to the psychosocial resources considered, our findings, as we expected, indicated that young people who possessed a positive internalized representation of their social relationships, along with a representation of support available to them in times of 
need, had greater immunity against loneliness during this crisis period. Namely, in this undesirable situation, where people had to give up many concrete aspects of their familial and social lives, the ability of young people to lean on a positive cognitive representation of their social world proved to be especially important to their well-being. Our finding supports much of the previously found evidence showing the contribution of different types of social support to psychological well-being, decreased mental distress, and decreased loneliness in routine times [46,56,88,89].

In line with our hypothesis, we found that optimism was strongly associated with decreased loneliness. Optimism is a trait that makes people more willing to be active in their efforts to alleviate their distress and make changes in the aspects of their lives that bring them unhappiness [48]: in this case, their loneliness. However, contrary to our hypothesis, the bivariate association observed between mastery and loneliness diminished once the entire set of explanatory variables was controlled for. Our findings indicated that although in routine times sense of mastery is strongly associated with decreased loneliness [54], its contribution during these stressful times seems to be less dependable. Considering the nature of the current crisis-that is, a rapidly evolving one, characterized by general and scientific uncertainty [90] — this finding might not be that surprising. Although sense of mastery refers to people's feeling of perceived control over the future, and their ability to cope with life stressors, the uncertainty associated with the pandemic and people's inability to control many aspects of their lives (employment, everyday life plans, leisure time activities, etc.) may have decreased their sense of mastery so that even for those who possessed a greater sense of mastery, it was not enough to defeat the pandemic-related loneliness. In line with this idea, Frankham et al. [91] suggest that psychological factors "are vulnerable to depletion in response to stress, in which they stop acting as a buffer with negative consequences for mental well-being" (p. 12).

However, our findings indicated that although mastery did not affect loneliness directly, it still moderated the financial strain-loneliness association. Namely, the effect of financial strain on loneliness was less pronounced among those with a greater sense of mastery. As the coefficient of mastery in the main effect model appeared insignificant, the finding here indicates that sense of mastery was a protective factor against loneliness only among young adults who reported being financially distressed. Pearlin et al. [60,62] suggest that psychological resources, in particularly mastery, can provide protection against stress, buffering the effects of the stressor on distress symptoms, namely, the health outcomes of the stressor. It may be that these young people's sense of mastery made them perceive their current economic distress as manageable and themselves as able to overcome this setback soon [60]. Their sense of control seems to have alleviated their sense of loneliness.

In sum, our findings here support the stress process model by demonstrating the association between financial strain and loneliness [61,62]. The findings partially support Pearlin and his colleagues' moderation model [60,61], suggesting that psychosocial resources can buffer the stress-distress association, with only sense of mastery being found to moderate the financial strain-loneliness link.

Along with its merits, this study has some limitations. First, it was based on an online snowball sample, which is a non-probabilistic sampling technique, a limitation that is typical of many COVID-19 studies, as many scholars have had to base their methods on digital questionnaires [92]. One of the main disadvantages of this method, as with other non-probabilistic sampling techniques, is selection bias. In an online snowball sample, there is a higher chance of participation among individuals who use social media more frequently and among those who have wider social networks [93]. Second, in the current study, more than half of the participants reported feeling lonely at some level. This rate is far higher than the rate reported in pre-COVID-19 studies among this age group (e.g., [94]). This finding might, to some extent, be attributable to the reduced stigmatization and broader social legitimacy of reporting loneliness in the wake of the pandemic. 


\section{Conclusions}

Our findings stress that COVID-19 health-related policies must include vast efforts to minimize the pandemic's damage to social and financial activities. In accordance with the sustainable development goals formulated by the United Nations [86] to promote mental health through prevention and treatment, governmental responses should be targeted toward the emotional effects of this pandemic. Interventions are needed to enhance social support for young adults during this crisis and to promote their sense that support is available for them when needed, as this factor has been shown to decrease loneliness. We would also suggest developing interventions to strengthen young people's mastery and optimism, two important psychological resources. Further, the current study stresses the large and sustained disparities in loneliness following the financial strain that emerged during the initial phase of the pandemic. Thus, interventions aimed at combating this financial strain should be seen as a major path toward preventing and decreasing loneliness during and after the pandemic. Such interventions include expanding entitlement for public support benefits, for example unemployment compensation, along with implementing active labor market programs targeted toward young adults. Given our findings that financial strain and its adverse consequences for loneliness cannot be overcome simply by virtue of psychological and social resources, direct action is needed to alleviate COVID-19-related financial strain among young adults, the cohort hit hardest by the current crisis [18].

Author Contributions: Conceptualization, T.R. and N.A.; methodology, N.A.; formal analysis, N.A.; data curation, T.R. and N.A.; writing —original draft preparation, T.R. and N.A.; writing-review and editing, T.R. All authors have read and agreed to the published version of the manuscript.

Funding: This research received no external funding.

Institutional Review Board Statement: The study was conducted according to the guidelines of the Declaration of Helsinki, and approved by the Ethics Committee of the Department of Social Work at Ben-Gurion University of the Negev (Approval number: \#50520, date: 5 May 2020).

Informed Consent Statement: Informed consent was obtained from all subjects involved in the study.

Data Availability Statement: The data that support the findings of this study are available from the corresponding author upon reasonable request.

Acknowledgments: The authors would like to thank the participants who volunteered to participate in the study.

Conflicts of Interest: The authors declare no conflict of interest.

\section{References}

1. World Health Organization. Coronavirus Disease (COVID-19) Situation Report No. 167. Available online: https:/ / reliefweb.int/ report/world/coronavirus-disease-covid-19-situation-report-167-5-july-2020 (accessed on 18 March 2021).

2. Hale, T.; Webster, A.; Petherick, A.; Phillips, T.; Kira, B. Oxford COVID-19 Government Response Tracker. Available online: https: / / www.bsg.ox.ac.uk/research/research-projects/coronavirus-governmentresponse-tracker (accessed on 17 March 2021).

3. Israeli Ministry of Health. COVID-19 Press Releases. Available online: https://www.gov.il/en/departments/news/?OfficeId=10 4cb0f4-d65a-4692-b590-94af928c19c0\&skip=0\&limit=10 (accessed on 9 March 2021).

4. Israeli Central Bureau of Statistics. Civil Resilience during the Coronavirus Crisis (Wave 1). Available online: https://www.cbs. gov.il/he/mediarelease/DocLib/2020/127/19_20_127b.pdf (accessed on 17 March 2021).

5. Herman, T.; Anavi, O. The Crisis of Confidence in the Government. Available online: https://www.idi.org.il/articles/32008 (accessed on 18 March 2021).

6. Achdut, L. The labor market in the Coronavirus crisis. Isr. Econ. Rev. 2020, 18, 59-79.

7. Bank of Israel. Special Analysis of the Research Division of the Bank of Israel: Unemployment Rate and Its Definition in the Corona Period. Available online: https://www.boi.org.il/he/NewsAndPublications/PressReleases/Pages/27-4-2020.aspx. (accessed on 7 March 2021).

8. Israeli Employment Service. Job Seekers Data-April 2020. Available online: https:/ / www.taasuka.gov.il/he/InfoAndPublications/ Pages/JobSeekersData.aspx (accessed on 10 March 2021). 
9. ILO (International Labour Organization). ILO Monitor: COVID-19 and the World of Work Fourth Edition Updated Estimates and Analysis. Available online: https://www.ilo.org/wcmsp5/groups/public/---dgreports/---dcomm/documents/briefingnote/ wcms_745963.pdf (accessed on 19 March 2020).

10. OECD. Record Rise in OECD Unemployment Rate in April 2020; OECD Publishing: Paris, France, 2020.

11. OECD. OECD Economic Outlook; OECD Publishing: Paris, France, 2020.

12. Achdut, L. COVID-19 and the Israeli Labor Market. ISR. J. Soc. Sec. 2020, 110, 1-20.

13. Israeli Employment Service. Labor Market Pulse Report-May 2020. Available online: https://www.taasuka.gov.il/he/ InfoAndPublications/IesFilesManagerReportsList/pirsumhodshi0520.pdf (accessed on 12 March 2021).

14. Israeli Central Bureau of Statistic (ICBS). Labour Force Survey Data. January 2021. Available online: https:/ /www.cbs.gov.il/en/ mediarelease/Pages/2021/Labour-Force-Survey-Data-January-2021.aspx. (accessed on 5 March 2021).

15. Endeweld, M.; Heller, O.; Karady, L. The impact of recession and policy on the standard of living, poverty and inequality-In the wake of the coronavirus. Soc. Secur. 2020, 110,1-22.

16. Endeweld, M.; Heller, O.; Karady, L. An Estimate of the Impact of the Corona Crisis on the Socio-Economic Situation. Available online: https://www.btl.gov.il/Publications/corona/Pages/mashber-calcali1206-5241.aspx (accessed on 19 March 2021).

17. Nelson, B.W.; Pettitt, A.; Flannery, J.E.; Allen, N.B. Rapid assessment of psychological and epidemiological correlates of COVID-19 concern, financial strain, and health-related behavior change in a large online sample. PLoS ONE. 2020, 15, e0241990. [CrossRef] [PubMed]

18. OECD. Risks that Matter 2020: The Long Reach of COVID-19; OECD Publishing: Paris, France, 2021.

19. Parolin, Z.; Curran, M.; Matsudaira, J.D.; Waldfogel, J.; Wimer, C. Monthly Poverty Rates in the United States during the COVID-19 Pandemic; Poverty and Social Policy Working Paper; Center on Poverty \& Social Policy: New York, NY, USA, 2020.

20. Glenn, N.M.; Nykiforuk, C.I. The time is now for public health to lead the way on addressing financial strain in Canada. Can. J. Public. Health 2020, 111, 984-987. [CrossRef]

21. Achdut, N.; Refaeli, T. Unemployment and psychological distress among young people during the covid-19 pandemic: Psychological resources and risk factors. Int. J. Environ. Res. Public Health 2020, 17, 7163. [CrossRef] [PubMed]

22. Wilson, J.M.; Lee, J.; Fitzgerald, H.N.; Oosterhoff, B.; Sevi, B.; Shook, N.J. Job insecurity and financial concern during the COVID-19 pandemic are associated with worse mental health. J. Occup. Environ Med. 2020, 62, 686-691. [CrossRef] [PubMed]

23. Canady, V.A. APA poll finds rise in anxiety related to COVID-19, election. Ment. Health Wkly. 2020, 30, 5. [CrossRef]

24. McGinty, E.E.; Presskreischer, R.; Han, H.; Barry, C.L. Psychological distress and loneliness reported by US adults in 2018 and April 2020. JAMA 2020, 324, 93-94. [CrossRef]

25. Horesh, D.; Lev-Ari, R.K.; Hasson-Ohayon, I. Risk factors for psychological distress during the COVID-19 pandemic in Israel: Loneliness, age, gender, and health status play an important role. Br. J. Health. Psychol. 2020, 25, 925-933. [CrossRef]

26. Luhmann, M.; Hawkley, L.C. Age differences in loneliness from late adolescence to oldest old age. Dev. Psychol. 2016, 52, 943-959. [CrossRef]

27. Matthews, T.; Danese, A.; Caspi, A.; Fisher, H.L.; Goldman-Mellor, S.; Kepa, A.; Arseneault, L. Lonely young adults in modern Britain: Findings from an epidemiological cohort study. Psychol. Med. 2019, 49, 268-277. [CrossRef]

28. Lisitsa, E.; Benjamin, K.S.; Chun, S.K.; Skalisky, J.; Hammond, L.E.; Mezulis, A.H. Loneliness among young adults during covid-19 pandemic: The mediational roles of social media use and social support seeking. J. Soc. Clin. Psychol. 2020, 39, 708-726. [CrossRef]

29. Courtin, E.; Knapp, M. Social isolation, loneliness and health in old age: A scoping review. Health Soc. Care Commun. 2017, 25, 799-812. [CrossRef]

30. European Commission. Loneliness-An Unequally Shared Burden in Europe. Available online: https://ec.europa.eu/jrc/sites/ jrcsh/files/fairness_pb2018_loneliness_jrc_i1.pdf (accessed on 21 March 2021).

31. Beutel, M.E.; Klein, E.M.; Brähler, E.; Reiner, I.; Jünger, C.; Michal, M.; Tibubos, A.N. Loneliness in the general population: Prevalence, determinants and relations to mental health. BMC Psychiatry 2017, 17, 97. [CrossRef] [PubMed]

32. Macdonald, S.J.; Nixon, J.; Deacon, L. 'Loneliness in the city': Examining socio-economics, loneliness and poor health in the North East of England. J. Public Health 2018, 165, 88-94. [CrossRef] [PubMed]

33. Park, N.S.; Lee, B.S.; Chiriboga, D.A.; Chung, S. Loneliness as a mediator in the relationship between social engagement and depressive symptoms: Age differences among community-dwelling Korean adults. Health Soc. Care Community 2019, 27, 706-716. [CrossRef]

34. Luchetti, M.; Lee, J.H.; Aschwanden, D.; Sesker, A.; Strickhouser, J.E.; Terracciano, A.; Sutin, A.R. The trajectory of loneliness in response to COVID-19. Am. Psychol. 2020, 75, 897-908. [CrossRef] [PubMed]

35. Lee, C.M.; Cadigan, J.M.; Rhew, I.C. Increases in loneliness among young adults during the COVID-19 pandemic and association with increases in mental health problems. J. Adolesc. Health 2020, 67, 714-717. [CrossRef]

36. Li, L.Z.; Wang, S. Prevalence and predictors of general psychiatric disorders and loneliness during COVID-19 in the United Kingdom. Psychiatry Res. 2020, 291, 113267. [CrossRef] [PubMed]

37. French, D.; Vigne, S. The causes and consequences of household financial strain: A systematic review. Int. Rev. Financ. Anal. 2019, 62, 150-156. [CrossRef]

38. De Koning, J.L.; Stathi, A.; Richards, S. Predictors of loneliness and different types of social isolation of rural-living older adults in the United Kingdom. Ageing Soc. 2016, 37, 2012-2043. [CrossRef] 
39. Victor, C.R.; Dobbs, C.; Gilhooly, K.; Burholt, V. Loneliness in mid-life and older adults from ethnic minority communities in England and Wales: Measure validation and prevalence estimates. Eur. J. Ageing. 2021, 18, 5-16. [CrossRef] [PubMed]

40. Visser, M.A.; El Fakiri, F. The prevalence and impact of risk factors for ethnic differences in loneliness. Eur. J. Public Health 2016, 26, 977-983. [CrossRef] [PubMed]

41. Hertz-Palmor, N.; Moore, T.M.; Gothelf, D.; DiDomenico, G.E.; Dekel, I.; Greenberg, D.; Barzilay, R. Association among income loss, financial strain and depressive symptoms during COVID-19: Evidence from two longitudinal studies. MedRxiv. 2020, 291, 1-8.

42. Elbogen, E.B.; Lanier, M.; Montgomery, A.E.; Strickland, S.; Wagner, H.R.; Tsai, J. Financial strain and suicide attempts in a nationally representative sample of US adults. Am. J. Epidemiol. 2020, 189, 1266-1274. [CrossRef]

43. Ferlander, S.; Mäkinen, I.H. Social capital, gender and self-rated health. Evidence from the Moscow Health Survey 2004. Soc. Sci. Med. 2009, 69, 1323-1332. [CrossRef]

44. Harpham, T.; Grant, E.; Thomas, E. Measuring social capital within health surveys: Key issues. Health Policy Plan. 2002, 17, 106-111. [CrossRef]

45. Lee, C.Y.S.; Goldstein, S.E. Loneliness, stress, and social support in young adulthood: Does the source of support matter? J. Youth Adolesc. 2016, 45, 568-580. [CrossRef]

46. Mellor, D.; Stokes, M.; Firth, L.; Hayashi, Y.; Cummins, R. Need for belonging, relationship satisfaction, loneliness, and life satisfaction. Pers. Individ. Differ. 2008, 45, 213-218. [CrossRef]

47. Nyqvist, F.; Victor, C.R.; Forsman, A.K.; Cattan, M. The association between social capital and loneliness in different age groups: A population-based study in Western Finland. BMC Public Health 2016, 16, 1-8. [CrossRef]

48. Scheier, M.F.; Carver, C.S. On the power of positive thinking: The benefits of being optimistic. Curr. Dir. Psychol. Sci. 1993, 2, 26-30. [CrossRef]

49. Lazarus, R.S.; Folkman, S. Stress, Appraisal, and Coping; Springer Publishing Company: New York, NY, USA, 1984.

50. Jackson, T.; Soderlind, A.; Weiss, K.E. Personality traits and quality of relationships as predictors of future loneliness among American college students. Soc. Behav. Pers. 2000, 28, 463-470. [CrossRef]

51. Rius-Ottenheim, N.; Kromhout, D.; Mast, R.C.; Zitman, F.G.; Geleijnse, J.M.; Giltay, E.J. Dispositional optimism and loneliness in older men. Int. J. Geriatr. Psychiatry 2012, 27, 151-159. [CrossRef] [PubMed]

52. Backe, I.F.; Patil, G.G.; Nes, R.B.; Clench-Aas, J. The relationship between physical functional limitations, and psychological distress: Considering a possible mediating role of pain, social support and sense of mastery. SSM Popul. Health 2018, 4, 153-163. [CrossRef] [PubMed]

53. Hobfoll, S.E.; Walfisch, S. Coping with a threat to life: A longitudinal study of self-concept, social support, and psychological distress. Am. J. Commun. Psychol. 1984, 12, 87-100. [CrossRef] [PubMed]

54. Ben-Zur, H. The association of mastery with loneliness: An integrative review. J. Individ. Differ. 2018, 39, 238-248. [CrossRef]

55. Niedzwiedz, C.L.; Richardson, E.A.; Tunstall, H.; Shortt, N.K.; Mitchell, R.J.; Pearce, J.R. The relationship between wealth and loneliness among older people across Europe: Is social participation protective? Prev. Med. 2016, 91, 24-31. [CrossRef] [PubMed]

56. Refaeli, T.; Achdut, N. Perceived poverty, perceived income adequacy and loneliness in Israeli young adults: Are social capital and neighbourhood capital resilience factors? Health Soc. Care Community 2020, 17, 7163-13177. [CrossRef] [PubMed]

57. Starkey, A.J.; Keane, C.R.; Terry, M.A.; Marx, J.H.; Ricci, E.M. Financial distress and depressive symptoms among African american women: Identifying financial priorities and needs and why it matters for mental health. J. Urban. Health 2012, 90, 83-100. [CrossRef] [PubMed]

58. Taylor, Z.E.; Jochem, R.; Early, D.R.; Conger, R.D.; Widaman, K.F.; Robins, R.W. Dispositional optimism: A psychological resource for Mexican-origin mothers experiencing economic stress. J. Fam. Psychol. 2012, 26, 133-139. [CrossRef]

59. Ennis, N.E.; Hobfoll, S.E.; Schröder, K.E.E. Money doesn't talk, it swears: How economic stress and resistance resources impact inner-city women's depressive mood. Am. J. Community Psychol. 2000, 28, 149-173. [CrossRef]

60. Pudrovska, T.; Schieman, S.; Pearlin, L.I.; Nguyen, K. The sense of mastery as a mediator and moderator in the association between economic hardship and health in late life. J. Aging Health 2005, 17, 634-660. [CrossRef]

61. Pearlin, L.I. The sociological study of stress. J. Health Soc. Behav. 1989, 30, 241-256. [CrossRef] [PubMed]

62. Pearlin, L.I.; Lieberman, M.A. Social sources of emotional distress. Res. Community Ment. Health 1979, 1, $217-248$.

63. Pearlin, L.I.; Schieman, S.; Fazio, E.M.; Meersman, S.C. Stress, health, and the life course: Some conceptual perspectives. J. Health Soc. Behav. 2005, 46, 205-219. [CrossRef]

64. Su, X.; Zhou, A.N.; Li, J.; Shi, L.; Huan, X.; Yan, H.; Wei, C. Depression, loneliness, and sexual risk-taking among HIVnegative/unknown men who have sex with men in China. Arch. Sex. Behav. 2018, 47, 1959-1968. [CrossRef] [PubMed]

65. Nicolaisen, M.; Thorsen, K. Who are lonely? Loneliness in different age groups (18-81 years old), using two measures of loneliness. Int. J. Aging Hum. Dev. 2014, 78, 229-257. [CrossRef]

66. Yang, K.; Victor, C.R. Age and loneliness in 25 European nations. Ageing Soc. 2011, 31, 1368-1388. [CrossRef]

67. Maia, I.; Monjardino, T.; Frias, B.; Canhão, H.; Cunha Branco, J.; Lucas, R.; Santos, A.C. Food insecurity in Portugal among middle- and older-aged adults at a time of economic crisis recovery: Prevalence and determinants. Food Nutr. Bull. 2019, 40, 504-513. [CrossRef]

68. Israeli Central Bureau of Statistics. Social Survey-Introduction and Methodological Appendix; Israeli Central Bureau of Statistics: Jerusalem, Israel, 2018. 
69. Achdut, N.; Sarid, O. Socio-economic status, self-rated health and mental health: The mediation effect of social participation on early-late midlife and older adults. Isr. J Health Policy Res. 2020, 9, 4. [CrossRef]

70. Buck-McFadyen, E.; Akhtar-Danesh, N.; Isaacs, S.; Leipert, B.; Strachan, P.; Valaitis, R. Social capital and self-rated health: A cross-sectional study of the general social survey data comparing rural and urban adults in Ontario. Health Soc. Care Community 2019, 27, 424-436. [CrossRef] [PubMed]

71. Torpe, L.; Lolle, H. Identifying social trust in cross-country analysis: Do we really measure the same? Soc. Indic. Res. 2011, 103, 481-500. [CrossRef]

72. Pearlin, L.; Schooler, C. The structure of coping. J. Health Social Behav. 1978, 19, 2-21. [CrossRef]

73. Scheier, M.F.; Carver, C.S.; Bridges, M.W. Distinguishing optimism from neuroticism (and trait anxiety, self-mastery and self-esteem): A reevaluation of the life orientation test. J. Pers. Soc. Psychol. 1994, 67, 1063-1087. [CrossRef]

74. Zeidner, M.; Ben-Zur, H. Individual differences in anxiety, coping, and post-traumatic stress in the aftermath of the Persian Gulf War. Pers. Individ. Differ. 1994, 16, 459-476. [CrossRef]

75. Tabachnick, B.G.; Fidell, L.S. Using Multivariate Statistics, 5th ed.; Pearson: Boston, CA, USA, 2007.

76. Kapucu, T.; Ilk, O.; Batmaz, İ. A Categorical Principal Component Regression on Computer-Assisted Instruction in Probability Domain; Springer International Publishing: Cham, Switzerland, 2018.

77. Vilela, A.; Monteiro, B.; Correia, E. Categorical Principal Component Analysis (CATPCA): A Statistical Method for Sensory Data Treatment Applied to the Sensory Profile of Port Wines. In Proceedings of the 40th World Congress of Vine and Wine: Vine \& Wine, Science and Economy, Culture and Education, Sofia, Bulgaria, 29 May-2 June 2017.

78. DiStefano, C.; Zhu, M.; Mindrila, D. Understanding and using factor scores: Considerations for the applied researcher. Pract. Assess. Res. Eval. 2009, 14, 20.

79. Horigian, V.E.; Schmidt, R.D.; Feaster, D.J. Loneliness, mental health, and substance use among US young adults during COVID-19. J. Psychoact. Drugs 2020, 53, 1-9. [CrossRef]

80. Vanderbruggen, N.; Matthys, F.; Van Laere, S.; Zeeuws, D.; Santermans, L.; Van den Ameele, S.; Crunelle, C.L. Self-reported alcohol, tobacco, and cannabis use during COVID-19 lockdown measures: Results from a web-based survey. Eur. Addict. Res. 2020, 26, 309-315. [CrossRef]

81. González-Sanguino, C.; Ausín, B.; Castellanos, M.Á.; Saiz, J.; López-Gómez, A.; Ugidos, C.; Muñoz, M. Mental health consequences during the initial stage of the 2020 Coronavirus pandemic (COVID-19) in Spain. Brain Behav. Immun. 2020, 87, 172-176. [CrossRef]

82. Palgi, Y.; Shrira, A.; Ring, L.; Bodner, E.; Avidor, S.; Bergman, Y.; Hoffman, Y. The loneliness pandemic: Loneliness and other concomitants of depression, anxiety and their comorbidity during the COVID-19 outbreak. J. Affect. Disord. 2020, 275, 109-111. [CrossRef]

83. Mental Health Foundation. Loneliness during Coronavirus. Available online: https://www.mentalhealth.org.uk/coronavirus / coping-with-loneliness (accessed on 14 March 2021).

84. Pearlin, L.I. The stress process revisited. In Handbook of the Sociology of Mental Health, 1st ed.; Aneshensel, C.S., Phelan, J.C., Eds.; Springer: Boston, MA, USA, 1999; pp. 395-415.

85. Dawel, A.; Shou, Y.; Smithson, M.; Cherbuin, N.; Banfield, M.; Calear, A.L.; Batterham, P.J. The effect of COVID-19 on mental health and wellbeing in a representative sample of Australian adults. Front. Psychiatry 2020, 11, 579985. [CrossRef] [PubMed]

86. United Nations. The Sustainable Development Goals: Our Framework for COVID-19 Recovery. Available online: https: //www.un.org/sustainabledevelopment/sdgs-framework-for-covid-19-recovery/ (accessed on 11 March 2021).

87. Hagger, M.S.; Keech, J.J.; Hamilton, K. Managing stress during the coronavirus disease 2019 pandemic and beyond: Reappraisal and mindset approaches. Stress. Health 2020, 36, 396-401. [CrossRef]

88. Ren, Y.; Ji, B. Correlation between perceived social support and loneliness among chinese adolescents: Mediating effects of psychological capital. Psychiatr. Danub. 2019, 31, 421-428. [CrossRef] [PubMed]

89. Ward, E.; Mengesha, M. Depression in African American men: A review of what we know and where we need to go from here. Am. J. Orthopsychiatry 2013, 83 Pt 3, 386-397. [CrossRef]

90. Balog-Way, D.H.P.; McComas, K.A. COVID-19: Reflections on trust, tradeoffs, and preparedness. J. Risk Res. 2020, 23, 1-11. [CrossRef]

91. Frankham, C.; Richardson, T.; Maguire, N. Psychological factors associated with financial hardship and mental health: A systematic review. Clin. Psychol. Rev. 2020, 77, 101832. [CrossRef]

92. Remnant, F. Qualitative Research in a Pandemic. Available online: https://bathsdr.org/qualitative-research-in-a-pandemic/ (accessed on 17 March 2021).

93. Baltar, F.; Brunet, I. Social research 2.0: Virtual snowball sampling method using Facebook. Internet. Res. 2012, 22, 57-74. [CrossRef]

94. Achdut, N.; Refaeli, T. An ethnocultural perspective on loneliness in young adulthood: A population-based study in Israel. Sociol. Health Illn. 2021. [CrossRef] 